\title{
STORYTELLING COMO ESTRATÉGIA PEDAGÓGICA PARA EDUCAÇÃo JURÍDICA
}

\section{Resumo}

Vanessa de Oliveira Amorim ${ }^{1}$ Rogério Monteles da Costa ${ }^{2}$

A pesquisa investiga o storytelling como forma de abordar um dado componente curricular em aula expositiva no curso de graduação em Direito. No ensino jurídico, há obrigatoriedade de uso de metodologias ativas com a vigência da Resolução n. 5, 17 de dezembro de 2018, do Conselho Nacional de Educação. A investigação, nesse contexto, parte da possibilidade de utilizar o storytelling, arte de contar histórias, como forma de transmissão dos componentes curriculares. O percurso estudado concentra-se em revisão da literatura, tendo, por conclusão, que no ensino do direito, a narração de histórias é uma ferramenta importante para o processo de ensino-aprendizagem.

Palavras-chave: Storytelling. Narrativas. Metodologia ativa. Ensino. Aprendizagem. Direito.

\section{STORYTELLING AS A PEDAGOGICAL STRATEGY FOR LEGAL EDUCATION}

\begin{abstract}
The research investigates storytelling to approach a given curricular component in an expository class in the undergraduate Law course. In legal education, it is mandatory to use active methodologies under Resolution n. 5, December 17, 2018, of the National Education Council. The investigation, in this context, starts from the possibility of using storytelling, the art of storytelling, as a way of transmitting curricular components. The studied path focuses on literature review, having, by conclusion, that in the teaching of law, storytelling is an important tool for the teaching-learning process.
\end{abstract}

Keywords: Storytelling. Narratives. Active methodology. Teaching. Learning. Law.

\section{INTRODUÇÃO}

A presente pesquisa investiga, na segunda década do século XXI, no Brasil, o uso do método de ensino participativo do storytelling no curso de graduação em Direito. O problema da pesquisa é saber em que medida o storytelling pode ser utilizado em uma aula expositiva para o ensino do Direito.

\footnotetext{
${ }^{1}$ Doutoranda em Direito Constitucional na Universidade de Fortaleza, Fortaleza, CE, Brasil; Mestra em Direito e Gestão de Conflitos pela Universidade de Fortaleza, Fortaleza, CE, Brasil. E-mail: vanessaamorim@edu.unifor.br

${ }^{2}$ Doutorando em Direito Constitucional na Universidade de Fortaleza, Fortaleza, CE, Brasil; Mestre em Direito e Gestão de Conflitos pela Universidade de Fortaleza, Fortaleza, CE, Brasil. E-mail: rmonteles@edu.unifor.br

3 Mestrando em Direito Constitucional na Universidade de Fortaleza, Fortaleza, CE, Brasil. E-mail: mviniciusnr9@gmail.com
} 
O ensino jurídico no Brasil tem passado por mudanças provocadas pelo contexto tecnológico da $4^{\mathrm{a}}$ Revolução Industrial, movimento marcado pela fusão entre os domínios físicos, digitais e biológicos, no qual as profissões jurídicas têm se tornado cada vez mais heterogêneas, de forma a exigir dos estudantes, além das unidades de conhecimento, o desenvolvimento de competências e habilidades, tais como; colaboração, resolução de problemas complexos, comunicação, dentre outras.

Estas competências e habilidades podem ser desenvolvidas pelo ensino jurídico participativo, notadamente, a partir da Resolução n. 5, de 17 de dezembro de 2018, do Ministério da Educação, que regulamenta as novas Diretrizes Curriculares Nacionais do curso de graduação em Direito.

Nesse quadro, o objetivo da pesquisa é analisar como o storytelling, enquanto metodologia participativa, é capaz de contribuir para o ensino jurídico. Para isso, analisa-se a evolução do ensino do Direito no Brasil e os métodos ativos de ensino. Em seguida, o conceito de storytelling, isto é, a arte de contar histórias, e sua relação com o aprendizado sob a ótica da argumentação baseada na retórica de Aristóteles; e, por fim, como o storytelling pode ser usado como método de ensino jurídico.

O desenvolvimento da pesquisa compreendeu a revisão da literatura conforme levantamento ao final indicado, tendo como referencial teórico para os conceitos de métodos de ensino Ghirardi e Feferbaum e o conceito de storytelling apresentado por Valença e Tostes.

Para tanto, o trabalho está dividido em três seções: primeiro, apresenta-se uma exposição sobre a evolução dos cursos jurídicos no Brasil e sua relação com as metodologias de ensino; após, o artigo trata sobre o storytelling e sua relação com o aprendizado em geral; ao final, apresenta proposta de utilização de storytelling para o ensino jurídico.

Nesse contexto, justifica-se a relevância da pesquisa haja vista que se apresenta uma proposta de utilização estratégica do storytelling no ensino jurídico; à ciência, com debates acerca desse método de ensino; e à sociedade, que terá egressos com formação desejada pela Resolução n. 5/2018 do Conselho Nacional de Educação.

\section{O ENSINO DO DIREITO NO BRASIL E AS METODOLOGIAS DE ENSINO- APRENDIZAGEM}

A gênese dos cursos de jurídicos no Brasil coincide com o contexto histórico-político da independência em relação à Coroa Portuguesa em 1822. A construção do estado monárquico desencadeou a criação dos primeiros cursos de graduação em Direito por meio da Carta de lei 
de 11 de agosto de 1827, sancionada por Pedro I, que criou os dois primeiros cursos jurídicos no Brasil, um na cidade de Olinda (PE) e outro em São Paulo (SP) (BRASIL, 1827).

O curso criado pela Carta de lei de 11 de agosto de 1827 tinha duração de cinco anos, dividido em nove cadeiras, ao final, habilitava o concluinte a receber o grau de bacharel em Direito. Após formado, caso desejasse defender publicamente uma tese, escolhida dentre as matérias do curso, teria conferido o grau de Doutor e era escolhido para Lente ${ }^{4}$ (BRASIL, 1827).

A legislação dividia o curso da seguinte forma: no primeiro ano do curso haveria como $1^{\text {a }}$ Cadeira: Direito Natural, Direito Público, Análise da Constituição do Império, Direitos da Gentes e Diplomacia; no segundo ano, a $1^{\mathrm{a}}$ Cadeira eram a continuação do ano anterior e $2^{\mathrm{a}}$ Cadeira, ensinava-se: Direito Público Eclesiástico; no terceiro ano, como $1^{\text {a }}$ Cadeira havia: Direito Civil e $2^{\mathrm{a}}$ Cadeira o ensino era sobre: Direito Criminal com Teoria do Processo Criminal; no quarto ano, como $1^{\mathrm{a}}$ Cadeira: Direito Civil e $2^{\mathrm{a}}$. Cadeira: Direito Mercantil e Marítimo; e finalmente, no quinto ano, como $1^{\mathrm{a}}$ Cadeira ensinava-se: Economia Política e $2^{\mathrm{a}}$ Cadeira: Teoria e prática do processo adotado pelas leis do Império ${ }^{5}$ (BRASIL, 1827).

Os cursos de Direito criados no Brasil possuem como base a Universidade de Coimbra, os primeiros professores eram ex-alunos de Coimbra bem como alguns dos primeiros alunos de lá vieram transferidos. Não obstante Murilo de Carvalho (2003, p. 76) aponta que houveram reformas no conteúdo de suas disciplinas, para atender às necessidades da colônia, tais como, abandono do direito romano, ênfase em matérias ligadas ao direito marítimo e mercantil e à economia política e a formação de advogados, deputados, senadores, diplomatas etc.

Em 1889, com o advento da República no Brasil, o currículo dos cursos de Direito passou por alterações, apontada como primeira mudança significativa a extinção da cadeira de direito público eclesiástico, diante da desvinculação da igreja com o estado, bem assim a inserção das cadeiras de Filosofia e História do Direito e Legislação Comparada sobre Direito Privado (DINIZ, 2018, p. 72). A Lei n. 314, de 30 de outubro de 1895, apresentou nova distribuição das matérias do curso em 19 cadeiras $^{6}$ (BRASIL, 1895).

\footnotetext{
${ }^{4}$ Expressão que designava o professor.

${ }^{5}$ Clóvis Bevilaqua comentando o programa aponta que as cadeiras incluíam tantas matérias que poderiam repartir-se em três ou mais, bem como era certa a impossibilidade de serem cumpridas todas as disciplinas, em um só ano, de modo que poderia o professor oferecer delas noções sucintas (VENANCIO FILHO, 2011, p. 30).

${ }^{6} \mathrm{O}$ ensino de graduação em Direito foi dividido em cinco anos, distribuídos nas seguintes cadeiras: $1^{\circ}$ ano: Filosofia do direito, Direito romano, Direito público e constitucional; $2^{\circ}$ ano: Direito civil, Direito criminal,
} 
Novas alterações legislativas foram promovidas no currículo mínimo do curso de Direito. A regra do currículo mínimo vigorou de 1962 até 2004, quando pela Resolução n. 9, 29 de setembro de 2004, o Conselho Nacional de Educação instituiu a regra das diretrizes curriculares. Os eixos de formação de tais diretrizes eram o fundamental, com as disciplinas antropologia, ciência política, economia, ética, filosofia, história, psicologia e sociologia; o profissional: direito constitucional, direito administrativo, direito tributário, direito penal, direito civil, direito empresarial, direito do trabalho, direito internacional e direito processual; e o eixo de formação prática: estágio curricular, trabalho de conclusão de curso e atividades complementares. (DINIZ, 2018, p. 73)

A Resolução n. 9, 29 de setembro de 2004, do Conselho Nacional de Educação foi revogada pela Resolução n. 5, 17 de dezembro de 2018, do Conselho Nacional de Educação, que institui as "Diretrizes Curriculares Nacionais do Curso de Graduação em Direito e dá outras providências", substituindo a menção a "eixos de formação", por "perspectivas formativas": formação geral, formação técnico-jurídica e a formação prático-profissional (BRASIL. CONSELHO NACIONAL DE EDUCAÇÃO, 2018).

A formação geral visa oferecer ao graduando os elementos fundamentais do Direito, em diálogo com as demais expressões do conhecimento filosófico e humanístico, das ciências sociais e das novas tecnologias da informação, abrangendo estudos de outras áreas formativas. A formação técnico-jurídica contempla o enfoque dogmático, o conhecimento e a aplicação, os conteúdos referentes às áreas de Teoria do Direito, Direito Constitucional, Direito Administrativo, Direito Tributário, Direito Penal, Direito Civil, Direito Empresarial, Direito do Trabalho, Direito Internacional, Direito Processual; Direito Previdenciário, Formas Consensuais de Solução de Conflitos. A formação pratico-profissional visa a integração entre a prática e os conteúdos teóricos desenvolvidos nas demais perspectivas formativas (BRASIL. CONSELHO NACIONAL DE EDUCAÇÃO, 2018).

A Resolução CNE n. 5/2018 prevê que o curso de graduação em Direito deverá assegurar, no perfil do graduando, sólida formação geral, humanística, capacidade de análise, domínio de conceitos e da terminologia jurídica, de argumentação, interpretação e valorização dos fenômenos jurídicos e sociais, além do domínio das formas consensuais de composição de

Direito internacional público e diplomacia, Economia política; $3^{\circ}$ ano: Direito civil, Direito criminal, Ciência das finanças e contabilidade do Estado e Direito comercial; $4^{\circ}$ ano: Direito civil, Direito comercial, Teoria do processo civil, comercial e criminal, Medicina pública; $5^{\circ}$ ano: Prática forense, Ciência da administração e direito administrativo, História do direito e especialmente do direito nacional e Legislação comparada sobre o direito privado. 
conflitos, por meio de uma postura reflexiva e crítica que fomente a capacidade e a aptidão para a aprendizagem, autônoma e dinâmica, indispensável ao exercício do Direito, à prestação da justiça e ao desenvolvimento da cidadania. No mesmo sentido, o parágrafo único do artigo

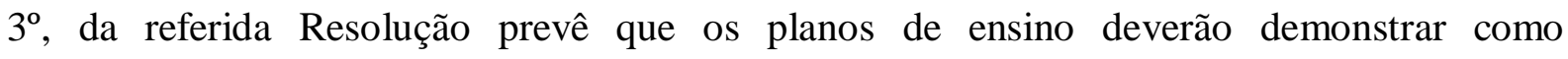
contribuirão para a adequada formação do graduando em face do perfil almejado pelo curso (BRASIL. CONSELHO NACIONAL DE EDUCAÇÃO, 2018).

Os planos de ensino devem conter os objetivos do respectivo componente curricular, os conteúdos, as atividades a serem desenvolvidas, as competências a serem trabalhadas, as metodologias de ensino e aprendizagem, os critérios de avaliação dos alunos e o cronograma dos encontros presenciais ou remotos $\mathrm{e}$ as referências básicas e complementares (RODRIGUES, 2019, p. 69).

A novidade da Resolução CNE n. 5/2018 é a obrigatoriedade da presença de metodologias ativas nos planos de ensino. A previsão está no artigo $2^{\circ}$, parágrafo $1^{\circ}$, inciso VI, que traz a exigência de que o projeto pedagógico tenha como um de seus elementos estruturais, os modos de integração entre teoria e prática, especificando as metodologias ativas utilizadas (BRASIL. CONSELHO NACIONAL DE EDUCAÇÃO, 2018).

$\mathrm{O}$ artigo $5^{\circ}$, parágrafo $2^{\circ}$ da mesma Resolução MEC n. 5/2018, estabelece que o projeto pedagógico incluirá as três perspectivas formativas (geral, técnico-jurídica e práticoprofissional $)^{7}$, considerados os domínios estruturantes necessários à formação jurídica, aos problemas emergentes e transdisciplinares e aos novos desafios de ensino e pesquisa que se estabeleçam para a formação pretendida (BRASIL. CONSELHO NACIONAL DE EDUCAÇÃO, 2018).

Masetto e Zukowsky-Tavares (2013, p. 35) apontam que desde as últimas décadas do século XX, a sociedade passa por profundas alterações promovidas pela revolução das tecnologias de informação e comunicação (TICs), que, afetam a vida cotidiana das pessoas,

\footnotetext{
7 A Resolução n. 5/2018, de dezembro de 2018, do Conselho Nacional de Educação, prevê as seguintes perspectivas formativas: (i) formação geral, que visa oferecer ao graduando os elementos fundamentais do Direito, em diálogo com as demais expressões do conhecimento filosófico e humanístico, das ciências sociais e das novas tecnologias da informação, envolvendo ainda saberes de outras áreas formativas, tais como: Antropologia, Ciência Política, Economia, Ética, Filosofia, História, Psicologia e Sociologia; (ii) formação técnico-jurídica, que abrange, o enfoque dogmático, bem como o conhecimento e a aplicação, observadas as peculiaridades dos diversos ramos do Direito, de qualquer natureza, estudados sistematicamente e contextualizados segundo a sua evolução e aplicação às mudanças sociais, econômicas, políticas e culturais do Brasil e suas relações internacionais; e (iii) formação prático-profissional, que objetiva a integração entre a prática e os conteúdos teóricos desenvolvidos nas demais perspectivas formativas, especialmente nas atividades relacionadas com a prática jurídica e o trabalho de curso (BRASIL. CONSELHO NACIONAL DE EDUCAÇÃO, 2018).
} 
atingindo, assim, aspectos da vida universitária, qual seja, a construção e socialização do conhecimento, desenvolvimento da pesquisa, a formação de profissionais competentes e cidadãos, revisão das carreiras profissionais e exigências de responsabilidade social.

Nesse sentido, tradicionalmente, o exercício da cátedra se ancorava principalmente no monopólio exclusivo da informação pelo professor e ao aluno o papel de receptor passivo (método expositivo). As alterações proporcionadas pela inovação têm dado lugar a uma postura cada vez mais ativa do aluno em buscar a informação, dentro e fora de sala de aula, no sentido de transformar a si próprio em uma ferramenta de ensino, inclusive para o professor. A participação dos alunos durante as aulas, mesmo uma simples dúvida, antes inadmissível, deu lugar, por exemplo, à aula debate, em que professor e alunos são livres para trazer à sala de aula dúvidas práticas, casos reais.

Focar no aluno como protagonista da construção do próprio conhecimento significa ir além e transmitir o conteúdo. O planejamento de um curso participativo passa pelo que Marina Feferbaum (2020, p. 66) de responder a pergunta do "momento zero", qual seja, "O que queremos que nossos estudantes aprendam"?. É a resposta à essa pergunta que revelarão os objetivos que nortearão as decisões acerca da escolha dos métodos de ensino, dos instrumentos de avaliação e das demais que serão necessárias na relação professor-aluno.

A etapa seguinte consiste na escolha dos métodos de ensino adequados para fomentar os objetivos traçados. Os métodos de ensino, portanto, são procedimentos que servem à prática de ensino com vista a concretizar os objetivos de aprendizagem (FEFERBAUM, 2020, p. 95). Ghirardi (2009, p. VIII) apresenta as seguintes metodologias participativas: o Ensino por Problema (Problem Based Learning - PBL), Role-Play, o Método do Caso, o Debate em sala de aula, o Diálogo Socrático, o Seminário como técnica de ensino e as Clínicas de Direito.

Essa não é uma lista exaustiva das técnicas de ensino participativo, a esses podem ser acrescentados o registro de entrada/registro de saída; Design Thinking; Dramatização; Exercícios; Exposição com atividades de retorno; Fishbowl (Aquário); Grupo de Verbalização/Grupo de Oralização; Jogos e Gamificação; Estudo de caso; Aprendizagem baseada em projetos; Simulação e Storytelling (FEFERBAUM, 2020, p. 99-124).

Esta pesquisa concentra-se no uso do método do Storytelling, servindo-se, em certa medida, da estrutura apresentada na obra "Métodos de Ensino em Direito: conceitos para um debate” (2009), para apresentar a referida técnica de ensino: (1) singularidade do método; (2) eficácia da aprendizagem, com reflexos nas alternativas de avaliação do desempenho; (3) circunstâncias e contextos do aparecimento e da evolução do método; (4) papel do aluno e do 
professor na aula, no curso e na escola, para o método; (5) procedimentos, táticas e estratégias de aplicação; e (6) interação entre métodos distintos.

A etimologia da palavra storytelling significa em inglês o ato de contar histórias (story + telling). Ao utilizar-se da narrativa, o docente situa o aluno como expectador da narrativa possibilitando vivenciar experiências que possivelmente talvez não fossem impressas com o mesmo vigor caso essa transmissão de conhecimento tivesse se dado de forma tradicional.

\section{STOTRYTELLING: UMA RELAÇÃO ENTRE AS HISTÓRIAS E O APRENDIZADO}

Storytelling, como estratégia pedagógica, consiste no uso de narrativas com significado social ou cultural para promover a reflexão acerca de valores e valores, a fim de consolidar ideias abstratas por meio da percepção da relevância e significância de tais conceitos e valores a um grupo de indivíduos (M. VALENÇA; BALTHAZAR TOSTES, 2019 , p. 222-223)

Faz parte da essência do ser humano o ato de contar histórias. As histórias transformam, constroem, resgatam valores esquecidos e perpetuam a memória coletiva daquele que as escuta. O contador de histórias transmite por meio da narrativa a sua interpretação, produzindo sentido e leitura de mundo. Assim, figuras como as do sábio, do pajé, do xamã, do ancião ou assemelhados nas mais diversas culturas são reverenciados em seus grupos sociais, pois além da sabedoria contavam com a virtude da generosidade em transmitir esses ensinamentos através de histórias (SILVA, 2011, p. 7).

O narrador da história, através da retórica, assume em papel sutil de conselheiro, demonstrando à medida que desenvolve a história, desafios, provações e realizações vivenciadas pelo personagem, ficcional ou não. Este narrador possui um roteiro predefinido a percorrer, desde a definição da narrativa mais impactante que deseja dividir, até o contexto em que irá apresentar essas histórias aos ouvintes, de que forma irá narrar. O substrato que fundamenta toda essa narrativa é sua própria trajetória de vida que, de certa forma, se interliga com a própria história contada (SILVA, 2011, p. 14).

O filósofo grego Aristóteles (apud NASCIMENTO, 2015) criou o que podemos chamar de um passo a passo para atingir a persuasão diante de um determinado público (NASCIMENTO, 2015). Aristóteles observou que determinadas pessoas tinham poderes de persuasão maiores do que outras. Para compreender este fenômeno, desenvolveu o que hoje chamamos de triângulo da persuasão, distribuindo em cada vértice os três atributos da retórica 
que levavam a persuasão do ouvinte: ethos (ética, ou caráter moral), logos (lógica), páthos (emoção, disposição criada no ouvinte), muito embora essas três competências não tenham hierarquia ou preponderância entre si.

Combinando esses três fatores da retórica em diferentes proporções, Aristóteles afirmava que para atingir o objetivo da persuasão seria necessário utilizar o caráter moral (éthos) do orador, as disposições criadas por ele nos ouvintes (páthos) e o domínio que ele possui sobre o logos (lógica) (NASCIMENTO, 2015, p. 39).

A conclusão lógica do discurso seria o resultado do bom uso do éthos e páthos, o narrador poderia direcionar o público para o rumo desejado, porém a conclusão lógica somente poderia ser tomada individualmente por cada um dos ouvintes. Para obtenção dos melhores resultados em convencer o público Aristóteles afirmava ser necessário auxiliar o público na tomada das decisões lógicas.

O Éthos pode ser definido como a envergadura moral conferida ao narrador. O contexto em que o narrador se apresenta pode demonstrar se pode/deve ser digno de fé. São exemplos de tentativas de incremento do éthos quando o autor da narrativa afirma serem os fatos verdadeiros que ocorreram, sem nenhuma alteração; ou que acontecerem consigo e são narrados em primeira pessoa ou nas orelhas de livros científicos que listam outras publicações do autor, sua formação, carreira profissional e, portanto, a razão pela qual ele é qualificado para escrever o livro em questão.

Pode-se encontrar essa intencionalidade de aumentar o éthos no livro Código de da Vinci, de Dan Brown, pois na sua abertura, o autor afirma que todas as descrições de obras de arte, arquitetura, documentos e rituais secretos neste romance correspondem rigorosamente à realidade (BROWN, 2004). O uso abusivo dessa característica é evidente na propagação de notícias falsas nas redes sociais: valer-se de um grande nome de determinada área de ciência para falsamente a ele atribuir uma opinião ou conferir um tom jornalístico imparcial a canais ligados a determinado grupo político, o raciocínio é: é verdade porque está no jornal.

$\mathrm{O}$ ato de julgar, posicionar-se, não é estruturado apenas na lógica, uma vez que as decisões do público também perpassam por suas experiências pessoais. A narrativa tem que estar disposta de modo a inspirar confiança aos seus ouvintes. Para tanto Aristóteles afirma ser necessário o retórico aparentar: possuir prudência (phrónesis), virtude (aretế) e benevolência (eúnoia) (NASCIMENTO, 2015, p. 42).

Por sua vez, Páthos não possui uma palavra no português que corresponda ao seu conteúdo, todavia pode ser compreendido como o desafio, o medo, a trama, a injustiça e a 
provocação que conecta o ouvinte e o contador de história por meio da narrativa. Aristóteles lista paixões capazes de despertar o ouvinte à narrativa: ira, calma, amizade e inimizade, temor, confiança, vergonha e desvergonha, amabilidade ou favor, piedade, indignação, inveja, emulação. Esses sentimentos por sua vez não são surgem desvinculado da razão, esses sentimentos fazem parte de um conjunto de ferramentas utilizáveis na persuasão (NASCIMENTO, 2015, p. 46).

Definido o tema que se quer trabalhar a fim de transmitir determinado conhecimento; definido o os argumentos lógicos e os sentimentos e desafios que melhor se aplicariam à efetivação da melhor transmissão do conhecimento aos ouvintes, a próxima etapa consiste em elaborar a narrativa que pode ser real ou ficcional, ocorrer no presente, passado ou futuro. $\mathrm{O}$ narrador dever responder algumas perguntas: Quais são as questões mais relevantes? Como elas se relacionam? Como explicá-las de maneira clara? Quais são os enigmas? Quais são as principais controvérsias? (ANDERSON, 2016, p. 28).

Por exemplo, o professor ao ensinar os regimes de casamento pode, de forma tradicional, realizar a leitura dos artigos 1.658 e seguintes do Código Civil ou utilizar como estratégia pedagógica o storytelling para ilustrar por meio de uma história/estória estruturada com personagens, enredo, mensagem e conflito a unidade curricular sobre o regime de casamento, procedimento e efeitos. A construção dessa narrativa exige do professor mais tempo de aula, preparo prévio e experiência do que a mera apresentação e leitura dos artigos, porém a fixação na memória do aluno se dá de maneira muito mais profunda e perene.

Gordillo (1997, p. 199-205) registra a diferença entre "clase magistral" e "clase ativa", em tradução livre, "aula do mestre" e "aula ativa", sendo o critério de distinção a atividade de aprendizagem do aluno. Na aula ativa, o professor dialoga com os alunos e promove questionamentos que os instigam, interrogam e geram perguntas visando fomentar a participação durante a exposição do assunto, a transmissão do conhecimento é dinâmica, evitando que o divague em seus pensamentos permanecendo numa atitude passiva. Na aula do mestre,

A aula do mestre tem o objetivo de transmitir a informação e esta pode ser útil em temas nos quais é conveniente um panorama introdutório, uma abordagem geral etc., mas um curso inteiro não deveria estar baseado nesta premissa, como aponta Gordillo (1997, p.199). Por sua vez, a aula ativa tem a vantagem secundária de produzir um professor mais descansado fisicamente e mais alerta e eficiente intelectualmente, o que o obriga a ter uma 
maior preparação para as tarefas com as quais complementará a aula expositiva (GORDILLO, 1997, p. 206).

A premissa subjacente ao aprendizado ativo sugere que o aprendizado é maior quando o que é estudado faz sentido ao estar associado a uma experiência real ou mental, contextualizada por valores e sentidos culturais e sociais (M. VALENÇA; BALTHAZAR TOSTES, 2019, p. 223).

Os psicólogos Jerome Bruner e Peg Neuhauser possuem estudos de que que o aprendizado oriundo de uma história bem contada é lembrado com mais precisão e por muito mais tempo do que o aprendizado derivado de fatos e números. Jerome Bruner (1980) sugere que os fatos têm 20 vezes mais chances de serem lembrados se fizerem parte de uma história (BORIS, 2019). Para isso basta pensar se é mais fácil lembrar um capítulo de um livro que acabou de ler ou uma história engraçada que alguém lhe contou.

Os pensamentos estão estruturados por meio de estórias/histórias, fornecendo ordem, gerando sentimentos. Os estudos da neurociência indicam que células cerebrais (neurôniosespelho) disparam quando estimuladas por narrativas, imagens de ressonância magnética demonstram que no cérebro do ouvinte são ativadas a mesmas áreas do narrador (WALLENTIN et al., 2011).

Valença e Tostes (2019, p. 226-228) identificam três contribuições centrais do uso da metodologia do storytelling para um ambiente pedagógico apropriado à construção do conhecimento (i) o empoderamento do narrador e da audiência (desfazendo-se a relação verticalizada entre autoridade que ensina e espectador que recebe a informação); (ii) a possibilidade de destacar aspectos específicos para cada audiência e objetivo; e (iv) a contribuição que o storytelling oferece para sustentar conceitos abstratos e/ou complexos, aproximando-os da audiência e de sua realidade e contexto social.

\section{O USO DO STORYTELLING COMO MÉTODO DE ENSINO JURÍDICO}

Tomemos um exemplo de dinâmica em sala de aula utilizando a técnica de ensino storytelling para iniciar a discussão. Esta atividade, desenvolvida no contexto de um curso de direito, pode ser descrita do seguinte modo:

João estava juntando algumas economias para comprar um carro novo para utilizar com sua família. Depois de passar por algumas lojas, encontrou o veículo. Utilizou suas economias como entrada e financiou o restante em 60 meses. Após alguns meses, João ficou desempregado e "passou o carro e as prestações para frente". Todavia, Marcelo, que 
comprou o carro de João deixou de pagar as parcelas. João havia firmado contrato de alienação fiduciária que é aquele no qual João transfere ao transfere ao credor fiduciário (instituição financeira que concedeu o financiamento) a propriedade do bem que adquiriu até o efetivo pagamento da dívida. O Banco Operações Capitais notificou João para pagar o débito. João ficou preocupado, pois tinha conhecimento que na Constituição Federal é permitida prisão civil do devedor de alimentos e do depositário infiel. Então João procurou o seu escritório de advocacia e o que você respondeu diante da pergunta feita por João 'Dr.(a), eu vou ser preso?'. Então, o advogado informou a João que não seria preso porque o Brasil é signatário do Pacto de San José da Costa Rica que só admite a prisão do devedor de alimentos. Assim, João não seria preso.

Essa poderia ser a introdução da aula do tema tratados internacionais da unidade curricular Direito Constitucional. O professor ao planejar a referida aula estabeleceu como objetivos que o aluno ao final da aula, pudesse identificar as categorias de tratados internacionais; compreender o mecanismo de ingresso do tratado no ordenamento jurídico; discutir a aplicação prática dos efeitos do tratado internacional que versa sobre direitos humanos.

O storytelling seria a ferramenta escolhida pelo docente para a concretização dos objetivos da aprendizagem, pois os discentes teriam a oportunidade de trabalhar as ideias, a relação entre elas, a troca de opinião, a empatia, a previsão de cenários, habilidades importantes para tomada de decisão na resolução de problemas (FEFERBAUM, 2020, p. 96).

Feferbaum (2020, p. 120) aponta que a história feita e apresentada pelos alunos, utilizando-se ou não de materiais (ex.: cordel, fábulas, etc.) é mais interessante na perspectiva da plenitude do método participativo, bem como aponta que a dinâmica de contar histórias seja seguida de um momento reflexivo sobre o que se falou ou escutou. Assim, a autora diz que o método serve para que o estudante possa desenvolver as seguintes competências: (i) antecipar cenários de realidade; (ii) integrar conceitos e interpretações de materiais jurídicos como exemplos da realidade; (iii) traduzir conceitos jurídicos para uma linguagem mais acessível; e (iv) identificar, analisar e problematizar interesses, atitudes, opiniões e ações na sociedade.

O storytelling pode ser associado a outros métodos de ensino que perpassam por fatos e processo comunicacional professor-aluno e/ou aluno-aluno, tais como o diálogo socrático (interação dialógica entre dois ou mais sujeitos), o debate, o estudo de caso (desenvolvimento 
da prática do raciocínio jurídico por meio da análise de decisões judiciais - casos reais), a música, o cinema, dependendo dos objetivos propostos para o ensino.

No estudo de caso de uma decisão judicial, por exemplo, o professor indica para os alunos investigarem os antecedentes das partes, bem como são incentivados a explorar as histórias apresentadas pelos litigantes, geralmente descritas pelo tribunal como os fatos. As histórias contadas pelas partes representam sua visão do conflito factual e podem ser apresentadas em sala de aula para discussão e análise.

Essa abordagem desafia o processo de ensino regular do direito, centrado no uso da decisão do tribunal como base para o debate e o diálogo em sala de aula. Assim, reconhece-se a importância da decisão do tribunal, e muda o foco para o aprendizado centrado no aluno, incentivando o aprendizado do aluno engajado, pois são orientados pelo professor para investigar os fatores históricos, sociais e políticos de fundo que cercam a disputa (BLISSENDEN, 2012).

Além disso, na perspectiva da formação prática do aluno, aprender a trabalhar em ambientes reais é um aspecto muitas vezes difícil na sua formação, a familiaridade com o ambiente profissional pode ocorrer mais facilmente por meio da escuta de histórias contadas por outros profissionais, e partir daí começar a dar sentido às realidades da prática e às relações entre a experiência atual e a experiência passada (MCDRURY; ALTERIO, 2003, p. $85)$.

Servindo o roteiro apresentado na obra "Métodos de Ensino em Direito: conceitos poro um debate” (2009), conforme exposto na seção 1 da pesquisa. A singularidade do método do storytelling consiste na criação de uma narrativa com personagens, envolvidos numa situação de conflito, desafio ou problema que se busca resolver.

A eficácia da aprendizagem é demonstrada em razão das evidências científicas de que as pessoas lembram-se de histórias melhor do que simplesmente conjuntos de fatos bem como as histórias oferecem descrições mais precisas da experiência humana do que argumentos jurídicos estéreis e as histórias persuadem de maneira que os argumentos doutrinários não persuadem e podem encorajar uma maior investigação das verdades narrativas (LEVIT, 2009).

O contexto do surgimento do storytelling enquanto método de ensino participativo como parte do currículo de muitas escolas e universidades iniciou nos anos de 1990, nos Estados Unidos. A evolução do uso método está relacionada ao fato de que o storytelling permite explorar diferentes contextos por meio da apresentação das informações passadas pela 
história, transmitindo a informação e aumentando a possibilidade de assimilação por meio de histórias. (TENÓRIO et al., 2020, p. 4).

O papel do aluno e do professor na aula, no curso e na escola, para o método deve ser criativo, colaborativo, exigindo o desenvolvimento de competências comunicacionais. McDrury e Alterio (2003, p. 109) apontam cinco habilidades fundamentais desenvolvidas com a utilização do método: (i) autoconsciência - nomear e processar os sentimentos relacionados a um evento; (ii) descrição de eventos - por meio do compartilhamento verbal ou da escrita ou desenho permitem que os eventos sejam recapturados; (iii) análise crítica envolve o enfoque em obter compreensão e explorar possibilidades e opções alternativas; (iv) a síntese - para garantir que haja integração de novos conhecimentos com conhecimentos anteriores, sendo a criatividade importante neste processo, pois permite que novas perspectivas e pensamento laterais sejam incorporados à equação de resolução de problemas; e (v) a avaliação - que envolve fazer julgamentos sobre o valor de algo, ou seja, permite que os alunos revisem os resultados reais e potenciais de eventos de prática ou a reflexão sobre eles e tomem decisões conscientes sobre ações futuras

Sugere-se como procedimento e estratégia de aplicação a seguinte proposta por Camargo (2018, p. 111-112): i) O professor fornece um problema, situação ou evento e solicita para que os alunos criem uma história a ser contada por meio dele. A história pode ser criada com base em pesquisa exploratória realizada pelos alunos, capazes de exemplificar uma situação real; ii) O storytelling deve ter, no mínimo, cinco elementos: a) personagem; b) o personagem deve ter desejos, necessidades, problemas, conflitos ou obstáculos; b) o personagem deve superar obstáculos; d) o personagem deve fazer escolhas; e) o personagem deve passar por um processo de transformação (para melhor); iii) Após criar a história, o grupo de alunos deve apresenta-la aos demais; iv) $\mathrm{O}$ professor encerrar a atividade promovendo uma discussão/debate.

Outra proposição para criação da história observa como estrutura os seguintes elementos: i) o enredo (o que vai acontecer); ii) estrutura (como vai acontecer); iii) personagens (a história acontece porque ocorre a interação entre os personagens e o antagonismo), iv) espaço (real ou ficcional); v) tempo histórico (ou ausência); vi) tempo de narrativa (ou ausência de marcação temporal); e vii) a linguagem (ACIOLI, 2019). É recorrente, no uso da ferramenta do storytelling, a construção de histórias em uma estrutura 
narrativa tripartite, em um modelo designado como a "jornada do herói"8 (CAMPBELL, 2005).

\section{CONCLUSÃO}

A narração de história tem sido usada para transmitir conhecimento e aprendizagem por toda a trajetória da vida humana. As histórias fornecem significado, contexto e compreensão, nessa perspectiva o método de contar histórias é incorporada ao ensino em sala de aula como forma de alcançar o aluno para a fixação do conhecimento e o desenvolvimento de competências e habilidades.

Dessa forma, o storytelling é um dos métodos de ensino que permite a transição entre o aprendizado passivo, tradicional, e o aprendizado ativo, no qual o aluno adota uma postura participativa do seu aprendizado. As histórias ficarão com as pessoas mais tempo do que estatísticas, fatos, leis, decretos etc.; assim, a diferença entre aprender o conceito abstrato de um instituto jurídico e a capacidade de resolver um problema no contexto de um exemplo da vida real.

No storytelling, o narrador visando propósitos específicos de aprendizado elabora, cria, narra uma história ficcional ou real cujo propósito final é transmitir o ensinamento de forma mais eficiente melhor fixando o conhecimento na memória do ouvinte. Nesse contexto, Aristóteles, na obra Retórica, organizou a narrativa subdividindo-a em três argumentos, éthos, páthos e logos, sendo que esses três fatores organizados em diferentes proporções têm por objetivo ampliar o poder de convencimento do narrador frente aos ouvintes.

O uso do storytelling no ensino jurídico, com método ativo de ensino, está em consonância com a Resolução n. 5, 17 de dezembro de 2018, do Conselho Nacional de Educação, que institui as "Diretrizes Curriculares Nacionais do Curso de Graduação em Direito". A metodologia exige do professor planejamento de aula tendo em vista que seu pode levar a um maior aprofundamento dos temas explanados. Igualmente a própria narrativa demanda um tempo de sala de aula que deve ser bem planejado de modo a contemplar os objetivos da unidade de ensino.

Desse modo, quando se utiliza histórias para trabalhar conteúdo do curso de Direito é possível refletir sobre o que aconteceu e obter insights sobre porque os eventos evoluíram

\footnotetext{
${ }^{8}$ A jornada é a representação mitológica do herói da fórmula representada nos rituais de passagem: separaçãoiniciação-retorno.
} 
dessa forma bem como oferecem oportunidades de explorar abordagens alternativas para a prática, estimulando e fortalecendo o papel reflexivo do aluno.

Conclui-se que, as técnicas de aprendizado ativo não significam o fim do ensino do método expositivo clássico, mas que devem combinar-se a fim de se obter a melhor preparação do aluno para a profissão jurídica que exercerá, consequentemente qualificado tanto pelo método tradicional com a doutrina, lei, artigo, como acompanhado metodologias ativas que propiciem o desenvolvimento de competências e habilidades para o exercício profissional.

Por fim, salienta-se que a presente pesquisa não tem o intuito de examinar todos os pontos referentes ao storytelling enquanto método ativo de ensino no curso de Direito, mas, sim, de fomentar as discussões acerca da necessidade de implementação dessa metodologia à formação do profissional do Direito do século XXI.

\section{REFERÊNCIAS}

ACIOLI, Socorro. Escrita Criativa. Mestrado Profissional Direito e Gestão de Conflitos. Universidade de Fortaleza. 2019.

ANDERSON, Chris. TED Talks: o guia oficial para falar em público. 1. ed. Rio de Janeiro: Intrínseca, 2016. E-book.

BLISSENDEN, Michael. The emerging use of storytelling as an alternative teaching methodology. Nottingham LJ , v. 19, 2010. Disponível em: https://ials.sas.ac.uk/ukcle/78.158.56.101/archive/law/resources/teaching-and-learningpractices/blissenden/index.html. Acesso em 10 jul. 2021.

BORIS, Vanessa. O que torna o storytelling tão eficaz para a aprendizagem? Harvard Business Review, [S. 1.], 2019. Disponível em: https://hbrbr.com.br/dicas/o-que-torna-ostorytelling-tao-eficaz-para-a-aprendizagem/. Acesso em: 17 maio. 2021.

BRASIL. CONSELHO NACIONAL DE EDUCAÇÃO. Resolução n. 5, de 17 de dezembro de 2018. Institui as Diretrizes Curriculares Nacionais do Curso de Graduação em Direito e dá outras providências. BRASIL: [s. n.], 2018. Disponível em: http://portal.mec.gov.br/index.php?option=com_docman\&view=download\&alias=104111 rces005-18\&category_slug=dezembro-2018-pdf\&Itemid=30192

BRASIL. Lei de 11 de agosto de 1827. Crêa dous Cursos de sciencias Juridicas e Sociaes, um na cidade de S. Paulo e outro na de Olinda. [S. 1.: s. n.] Disponível em: http://www.planalto.gov.br/ccivil_03/leis/lim/LIM.-11-08-1827.htm 
BRASIL. LEI N ${ }^{\text {o }}$ 314, DE 30 DE OUTUBRO DE 1895. Reorganisa o ensino das Faculdades de Direito. [S. 1.: s. n.] Disponível em: https://www2.camara.leg.br/legin/fed/lei/18241899/lei-314-30-outubro-1895-540752-publicacaooriginal-41651-pl.html. Acesso em: 16 maio. 2021.

BROWN, Dan. O Código Da Vinci. 1. ed. [S. 1.]: Arqueiro, 2004. E-book.

CAMARGO, Fausto. A sala de aula inovadora. Porto Alegre: Penso, 2018. E-book.

CAMPBELL, Joseph. O herói de mil faces. 10. ed. São Paulo: Cultrix/Pensamento, 2005.

CARVALHO, José Murilo de. A construção da ordem - Teatro das Sombras. Rio de Janeiro:

Civilização Brasileira, 2003.

DINIZ, Eduardo Albuquerque Rodrigues. A inserção dos mecanismos consensuais de conflito nas disciplinas jurídicas dos cursos de bacharelado em direito. 2018. - Dissertação. Universidade de Fortaleza. 2018, [s. 1.], 2018. Disponível em: https://uol.unifor.br/oul/conteudosite/?cdConteudo=9211658.

FEFERBAUM, Marina. Metodologias ativas em direito: guia prático para o ensino jurídico participativo e inovador. São Paulo: Atlas, 2020. E-book.

GORDILLO, Agustín. El método en derecho: aprender, enseñar, escribir, crear, hacer. Editorial Civitas. Madrid (España). 1997.

GHIRARDI, José Garcez. Métodos de Ensino em Direito: um conceito para debate. São Paulo: Saraiva, 2009. E-book.

LEVIT, Nancy. Legal Storytelling: The Theory and the Practice - Reflective Writing Across the Curriculum. Journal of the Legal Writing Institute, [S. 1.], v. 15, 2009. Disponível em: https://www.researchgate.net/publication/228205450_Legal_Storytelling_The_Theory_and_t he_Practice_-_Reflective_Writing_Across_the_Curriculum. Acesso em: 17 maio. 2021.

M. VALENÇA, Marcelo; BALTHAZAR TOSTES, Ana Paula. O Storytelling como ferramenta de aprendizado ativo. Carta Internacional, [S. 1.], v. 14, n. 2, p. 221-243, 2019. Disponível em: https://doi.org/10.21530/ci.v14n2.2019.917. Acesso em: 16 maio. 2021.

MASETTO, Marcos Tarciso; ZUKOWSKY-TAVARES, Cristina. Inovação e Universidade. In: GHIRARD, José Garcez; FEFERBAUM, Marina (organizadores) (org.). ENSINO DO DIREITO EM DEBATE REFLEXÕES A PARTIR DO $1^{\circ}$ SEMINÁRIO ENSINO JURÍDICO E FORMAÇÃO DOCENTE. [S. 1.: s. n.]. p. 33-46. E-book.

MCDRURY, Janice; ALTERIO, Maxine. Learning through storytelling higher education: Using reflection \& experience to improve learning. Learning Through Storytelling Higher Education: Using Reflection \& Experience To Improve Learning, [S. 1.], p. 1-199, 2003. 
Disponível em: https://doi.org/10.4324/9780203416655

NASCIMENTO, Joelson Santos. A RELAÇÃO ENTRE LÓGICA, PÁTHOS E ÉTHOS NA ARTE RETÓRICA DE ARISTÓTELES. ANAIS DE FILOSOFIA CLÁSSICA, [S. 1.], v. 9, n. 17, p. 38-60, 2015. Disponível em:

https://repositorio.ifs.edu.br/biblioteca/handle/123456789/1394. Acesso em: 16 maio. 2021.

RODRIGUES, Horácio Wanderlei. Curso de Direito no Brasil: Diretrizes Curriculares e Projeto Pedagógico. $1^{\text {a}}$ ed. ed. Florianópolis: Habitus, 2019. E-book.

SILVA, Rosimeire Cardoso Faria Soares da. Histórias para ler o mundo. 2011. UNIVERSIDADE DE SÃO PAULO, São Paulo, 2011. Disponível em: http://celacc.eca.usp.br/?q=pt-br/celacc-tcc/261/detalhe. Acesso em: 16 maio. 2021.

TENÓRIO, Nelson et al. Uso da Storytelling para a construção e o compartilhamento do conhecimento na educação. Educação por escrito, Porto Alegre, v. 11, n. 2, p. 1-10, 2020. Disponível em: https://doi.org/http://dx.doi.org/10.15448/2179-8435.2020.2.30601 OPEN VENÂNCIO FILHO. Das arcadas ao bacharelismo - 150 anos de ensino jurídico no Brasil. São Paulo: Perspectiva, 1982.

WALLENTIN, Mikkel et al. Amygdala and heart rate variability responses from listening to emotionally intense parts of a story. NeuroImage, [S. 1.], v. 58, n. 3, p. 963-973, 2011. Disponível em: https://doi.org/10.1016/j.neuroimage.2011.06.077. 